\title{
Causos Caipiras e Museu de História Natural: ferramentas para a construção do conceito de conservação
}

Tales Rednecks and Natural History Museum: tools for construction of the concept of conservation

Cuentos Campesinos y Museo de Historia Natural: herramientas para la construcción del concepto de conservación

Nathália Larissa do Prado

Graduanda em Ciências Biológicas, UFLA, Brasil.

nathbiologia92@gmail.com

Laise Vieira Gonçalves

Mestranda em Educação, UFSJ, Brasil.

laisebiologa@gmail.com

Antonio Fernandes Nascimento Junior

Professor Doutor, UFLA, Brasil.

toni_nascimento@yahoo.com.br 


\section{RESUMO}

O presente trabalho apresenta uma metodologia desenvolvida na disciplina de Metodologia do Ensino em Biologia, ofertada pelo curso de licenciatura em Ciências Biológicas da Universidade Federal de Lavras - MG que teve como objetivo o desenvolvimento de uma aula que consistiu na construção do conceito conservação da biodiversidade. Em um primeiro momento foi realizada uma visita guiada ao setor de exposição do Museu de História Natural da UFLA, seguido da exibição de uma foto de uma pele de onça-pintada exposta no museu. Num segundo momento foi utilizado um causo caipira 'Na Fazenda' criado por uma das integrantes do grupo a partir de pesquisas e de outros causos lidos. Essas ferramentas foram utilizadas como problematizadoras a fim de construir o conceito de conservação da biodiversidade. As discussões feitas durante a aula se mostraram potentes na construção deste conceito possibilitando reflexões transdisciplinares essenciais para uma formação mais completa. A atividade foi filmada e analisada. Ao final, pode-se sugerir que tal atividade cumpriu seu objetivo se mostrando uma ferramenta metodológica interessante e motivadora para a construção do conceito de conservação.

PALAVRAS-CHAVE: Educação Ambiental. Museu. Cultura Caipira.

\section{ABSTRACT}

This paper presents a methodology developed in the discipline of Biology Teaching Methodology, offered by the degree course in Biological Sciences at the Federal University of Lavras - MG which aimed to develop a class that consisted of the construction of the term biodiversity conservation. At first we carried out a guided tour of the exhibition sector of the Natural History Museum of UFLA, followed by the display of a picture of a jaguar skin exposed in the museum. Secondly we used a hick I cause 'The Farm' created by one of the group members from research and other stories read. These tools were used as problem-solving in order to build the concept of biodiversity conservation. The discussions made during class proved powerful in building this concept enabling essential transdisciplinary reflections for a more complete education. The activity was filmed and analyzed. In the end, it may be suggested that such activity accomplished his goal is showing an interesting and motivating methodological tool for the construction of the concept of conservation.

KEYWORDS: Environmental Education. Museum. Hick culture.

\section{RESUMEN}

En este trabajo se presenta una metodología desarrollada en la disciplina de la biología Metodología de la Enseñanza, que ofrece el grado de Ciencias Biológicas de la Universidad Federal de Lavras - MG que tiene por objeto el desarrollo de una clase que consistía en la construcción de la conservación de la biodiversidad plazo. En un primer momento se realizó una visita guiada por el sector de la exhibición del Museo de Historia Natural de UFLA, seguido de la visualización de una imagen de una piel de jaguar expuesto en el museo. En segundo lugar se utilizó un cateto causo 'La Granja' creado por uno de los miembros del grupo de investigación y otros cuentos leídos. Estas herramientas se utilizaron como la resolución de problemas con el fin de construir el concepto de conservación de la biodiversidad. Las discusiones realizadas durante la clase resultaron de gran alcance en la construcción de este concepto permite reflexiones transdisciplinarios esenciales para una educación más completa. La actividad fue filmado y se analizó. Al final, se puede sugerir que esta actividad logra su objetivo está mostrando una herramienta metodológica interesante y motivadora para la construcción del concepto de conservación.

PALABRAS CLAVE: Educación Ambiental. Museo. Cultura Hillbilly 


\section{INTRODUÇÃO}

Realizar trabalhos, projetos e aulas sobre Educação Ambiental nas escolas é de fundamental importância. A forma com que a Educação Ambiental é proposta nos Parâmetros Curriculares Nacionais (PCN) é feita por meio do tema transversal Meio Ambiente. Assim, ela deve permear todas as disciplinas proporcionando um grande leque de possibilidades de trabalhos educativos envolvendo o tema meio ambiente. A Educação Ambiental deve ser desenvolvida com a finalidade de ajudar os estudantes a construírem uma consciência global das questões relacionadas ao meio para que possam assumir posições sobre a proteção e melhoria do mesmo (BRASIL, 2001). Desta forma, é importante que seja possível atribuir significado aquilo que aprendem sobre a questão ambiental. E esse significado é resultado da ligação que o aluno estabelece entre o que aprende e a sua realidade cotidiana. Nas palavras de Dias (2004), a educação ambiental é considerada um processo constante pelo qual o indivíduo e a comunidade tomam consciência do seu meio ambiente e adquirem o conhecimento, os valores, as habilidades, as experiências e a determinação que os torna aptos a agir, individual e coletivamente, tentando resolver problemas ambientais presentes e futuros.

Existem várias maneiras de abordar e construir os conceitos da educação ambiental juntos aos alunos, neste caso trabalharemos com a construção do conceito de Conservação da Biodiversidade.

Percebe-se, ainda hoje, que a construção de conceitos está muito presa ao modo tradicional de ensino. A aula expositiva ainda continua sendo a principal estratégia e material de ensino. No entanto, o aprendizado pela prática, torna- se mais eficiente, especialmente no caso de temas ambientais, e ainda mais quando a abordagem dos conteúdos parte de acontecimentos e elementos do cotidiano dos alunos (DIAS, 2004).

Desta forma, existem outros espaços, além da sala de aula, que podem ser utilizados para auxiliar no processo de aprendizagem. Segundo Gohn (2006), os espaços educativos localizamse em territórios que acompanham as trajetórias de vida dos grupos e indivíduos, fora das escolas, em locais informais, locais onde há processos interativos intencionais.

Dentre as várias contribuições dos espaços não formais de educação, neste caso os museus, ressaltamos aqui a importância dos mesmos no processo de formação docente inicial e 
continuada e também no processo de aprendizagem e formação dos alunos. Em consonância com SABBATINI (2003), o papel dos museus de ciência vai muito além de aproximar as pessoas dos avanços tecnológicos e científicos. Esses espaços estão ligados à formação de um espírito crítico e de tomada de decisões que irão beneficiar a sociedade. Seu objetivo é mais que aproximar a população da ciência. É um ambiente cultural, de disseminação e alfabetização cientifica, que oferece aos sujeitos em formação bases para uma visão preocupada com a cidadania.

No entanto, os professores que fazem uso dessa ferramenta ainda constituem uma minoria. Segundo Krasilchik (2008), a maioria dos professores de Biologia considera de extrema valia as chamadas aulas práticas como o trabalho de campo, as excursões e visita aos museus. No entanto, são raros os professores que as realizam. Além disso, muitas destas atividades superestimam o potencial de lazer e entretenimento, ficando com pouco ou nenhum propósito ligado a aprendizados científicos e tecnológicos, o que pode acarretar uma percepção banalizada destas práticas.

Segundo Marandino (2004), para uma eficaz utilização dos museus e exposições como estratégias de ensino, é bom se conhecer o público alvo, em todas suas dimensões. No intuito de organizar as atividades, em seus aspectos teóricos e práticos. Possibilitando também, a participação ativa dos visitantes na elaboração das atividades do museu.

Neste trabalho, os elementos da cultura caipira auxiliaram no processo de construção do conceito de conservação e na busca pelo saber sobre outros modos de pensar e agir perante 0 meio em que os indivíduos estão inseridos. Para Diegues (2002), caipiras são sitiantes, meeiros e parceiros que sobrevivem precariamente em nichos entre as monoculturas do Sudeste e Centro-Oeste, em pequenas propriedades em que desenvolvem atividades agrícolas e de pequena pecuária, cuja produção se dirige para a subsistência familiar e para o mercado.

Segundo Darcy Ribeiro (1995), a área cultural caipira é um modo de vida que se difunde paulatinamente a partir das antigas áreas de mineração e dos núcleos de produção artesanal e de mantimentos que a supriam de manufaturas, de animais de serviço e outros bens. Esparramou-se, ainda segundo Darcy Ribeiro por toda a área florestal e campos naturais do Centro-Sul do país, desde São Paulo, Espírito Santo e o Estado do Rio de Janeiro, na costa, até Minas Gerais e Mato Grosso.

O caipira ainda sofre muito preconceito e precisamos desconstruir essa visão de que eles são atrasados, bobos, não aprendem nada. E Segundo Albuquerque Júnior (2007), este tipo de 


\section{da tilta Paulista}

preconceito é justamente aquele que marca alguém pelo simples fato deste pertencer ou advir de um território, de um espaço, de um lugar, de uma vila, de uma cidade, de uma província, de um estado, de uma região, de uma nação, de um país, de um continente considerado por outro ou outra, quase sempre mais poderoso, como sendo inferior, rústico, bárbaro, selvagem, atrasado, subdesenvolvido, menor, menos civilizado, feio, ignorante, culturalmente inferior, etc.

\section{OBJETIVO}

Neste contexto, o presente trabalho busca relatar uma atividade desenvolvida na disciplina Metodologia do Ensino em Biologia do curso de Licenciatura em Ciências Biológicas da Universidade Federal de Lavras - MG (UFLA). Esta teve como proposta a construção de uma aula que buscou construir o conceito de Conservação da Biodiversidade com o auxílio de um causo caipira e do Museu de História Natural (MHN) da UFLA. As estratégias metodológicas escolhidas para ministrar a aula foram a visita guiada no MHN, o causo caipira contado pela professora e a fotografia da pele da onça pintada exposta no museu.

\section{METODOLOGIA}

Inicialmente foi construída uma proposta de aula para a disciplina de Metodologia de Ensino em Biologia que consistia em desenvolver uma aula não expositiva e que também dialogasse com o Tema Transversal Pluralidade Cultural presente nos PCN. Esta foi apresentada, primeiramente, aos integrantes do Programa de Bolsas de Iniciação à Docência (PIBID) que colaboraram com sugestões para a elaboração de uma metodologia mais sólida e didática. Após esse processo, a atividade relatada foi realizada com os alunos da disciplina.

O desenvolvimento da aula se deu em cinco momentos. No primeiro, os alunos visitaram o Museu de História Natural com a mediação da professora. Eles observaram tudo o que estava exposto, e quando havia alguma dúvida os alunos perguntavam e a professora mediava a construção daquele aprendizado. No segundo momento, já em sala de aula, o professor perguntou o que chamou mais atenção dos alunos durante a visita. Após as respostas dos alunos, a professora indagou aos alunos o motivo de ter só a pele da onça exposta no museu. O que aconteceu com a onça? Todas as respostas iam de encontro ao tema da aula. No 


\section{da tilta Paulista}

terceiro momento, a professora contou um causo caipira, usando o vocabulário caipira, para exemplificar o que pode ter acontecido com a onça. O causo chamava-se "Na Fazenda", elaborado pela própria professora a partir de pesquisas e leitura de outros causos.

Num quarto momento, após o conto do causo, a professora problematizou outras causas para morte da onça. Através de perguntas norteadas como: Porque acontece a caça da onça? A caça contribui para a extinção da espécie? Quais outros elementos que contribuem para a extinção? Como é a relação do caipira com os animais? Porque no causo o personagem matou a onça? Trazendo elementos ambientais, sociais e econômicos tomamos como exemplo, a caça ilegal, o avanço econômico e a perda de áreas de proteção, atropelamentos, o esporte caça, a falta de informação, perda do habitat e ida dos animais para as proximidades de sítios e fazendas, etc.

No quinto momento foi proposta uma avaliação, onde os alunos, em grupo, elaboraram um causo sobre a conservação da biodiversidade e todos leram seus causos para mais uma conversa e finalização da atividade. Ao final, foi pedido que os alunos avaliassem, de forma escrita, a atividade realizada.

\section{RESULTADOS}

As descrições a seguir foram reescritas da avaliação da atividade desenvolvida na disciplina de Metodologia de Ensino. Os alunos não se identificaram durante esse processo. Para a identificação dos participantes foi utilizada a letra "P". As avaliações não estão descritas em sua integridade pois, as partes retiradas não são cabíveis de análises.

P1: [...] Eu achei muito instigante conhecer o causo e os animais. O ponto forte foi você conseguir juntar o causo que é cultural com a questão da conservação e extinção.

P2: [...] A começar pela disposição dos alunos em roda, que instiga os alunos a participar e os mais tímidos não ficam tão quietos quando colocados dessa maneira. A transversalidade ficou muito bem elaborada. Foi importante você ter trago a visão crítica sobre a preservação e a questão do caipira, que muitos acham que ele é o culpado, ignorante que não sabe de nada. 
P3: [...] Achei bem simples e direta a forma que você falou, todos conseguiram entender o que é o desmatamento e preservação, como podemos conservar. E você deixou os alunos imaginar o que é extinção e conservação, como acontece o desequilíbrio.

\subsection{A ANÁLISE}

Analisando as atitudes e as discussões feitas durante a aula, foi possível observar que a utilização de métodos não tradicionais de ensino, como o museu e o conto de causos, atrai à atenção dos alunos, desperta a curiosidade e o interesse do conteúdo a ser trabalhado. As Orientações Curriculares para o Ensino Médio indicam o desenvolvimento de práticas fora do espaço escolar, apontando-as como atividade motivadora para os alunos, já que saem do ambiente de aprendizagem formal (Brasil, 2006). O processo de mediação durante a visita se mostrou um fator ímpar, contribuindo para que os estudantes sanassem suas dúvidas e conhecessem o espaço do museu não somente como uma atividade de entretenimento, mas de possibilidade de construção de conhecimento. Para as pesquisadoras Boisvert e Slez (1994), a preocupação dos museus de ciências como espaços educacionais informais, vai além do entretenimento dos visitantes, e nesse sentido devem atrair e prender a atenção dos visitantes para que ocorra uma interação com o que está exposto e garantir um efetivo aprendizado dos conteúdos.

As problematizações e discussões feitas também levaram os alunos a refletirem questões importantes que contribuem para o despertar de uma visão crítica e reflexiva sendo estas fundamentais para a tomada de uma consciência ambiental crítica. Para Freire (2010), a conscientização é um processo de aprendizagem pelo diálogo, reflexão e ação no mundo. Movimento coletivo de expansão do conhecimento das relações que constituem a realidade, de leitura do mundo, conhecendo-o para transformá-lo e, ao transformá-lo, conhecê-lo.

Nas falas do P1 e P3 podemos destacar que a metodologia escolhida possibilitou a junção de aspectos culturais com o conceito a ser trabalhado motivando de forma positiva os estudantes. Em consonância com Costa (2008), os conhecimentos ou os "saberes locais", não só dos educandos, mas de seus familiares, podem servir de incentivo e âncora significativa para o ensino e aprendizagem do conteúdo curricular. E ainda, de acordo com, Ausubel (2002), esses conhecimentos resultam em um novo significado, fruto da integração ativa de novas ideias expressas de forma com aquelas que o educando já sabe. 


\section{da tilta Paulista}

No comentário do P2 destacamos a importância à contextualização da cultura caipira durante a prática, pois segundo Albuquerque Júnior (2007) o preconceito sofrido pelo caipira, é justamente aquele que marca alguém pelo simples fato deste pertencer ou advir de um território, de um espaço, de um lugar, de uma vila, de uma cidade, de uma província, de um estado, de uma região, de uma nação, de um país, de um continente considerado por outro ou outra, quase sempre mais poderoso, como sendo inferior, rústico, bárbaro, selvagem, atrasado, subdesenvolvido, menor, menos civilizado, feio, ignorante, culturalmente inferior, etc.

Ao colocar a cultura caipira como proposta de transversalidade, foi possível estabelecer relações entre os conceitos e o cotidiano além de conhecer outras formas de se manifestar o saber e aprender a relação de outros povos com o meio em que estão inseridos. Neste sentido, os elementos da cultura caipira auxiliaram no processo de construção do conceito de conservação e na busca pelo saber sobre outros modos de pensar e agir perante o meio em que os indivíduos estão inseridos. Assim, práticas pedagógicas como estas podem contribuir para as desconstruções de tais concepções bem como valorizar a cultura destes povos e potencializar a construção de conceitos científicos.

\section{CONCLUSÃo}

A partir da atividade realizada pode-se perceber que o ensino do conceito conservação e extinção utilizando métodos não expositivos, neste caso o conto de causos e a visita guiada ao museu, pode ser muito viável e contribui de forma positiva atraindo a atenção do aluno e incentivando o interesse pelo assunto explicado.

Assim, a partir da prática realizada, pode-se sugerir que esta contribuiu para uma construção mais significativa do conceito de conservação possibilitando a tomada de uma consciência ambiental. As reflexões transdisciplinares se mostraram essenciais para uma formação mais completa, bem como o desenvolvimento de pensamento e ações críticas e autônomas sendo estas questões fundamentais para formação de professores e para a inserção de tais temáticas no ambiente escolar.

\section{AGRADECIMENTO}


FAPEMIG e CAPES/PIBID

\section{REFERÊNCIAS}

ALBUQUERQUE JÚNIOR, D. M. Preconceito contra a origem geográfica e de lugar: as fronteiras da discórdia. São Paulo: Cortez, 2007.

Ausubel, D. P. Adquisición y retención del conocimiento. Una perspectiva cognitiva. Ed. Paidós. Barcelona. 2002.

BRASIL. Parâmetros Curriculares Nacionais: meio ambiente. 3. ed Brasília-DF: Ministério da Educação. Secretaria da Educação Fundamental, 2001.

BRASIL. Linguagens, códigos e suas tecnologias / Secretaria de Educação Básica. - Brasília: Ministério da Educação, Secretaria de Educação Básica, 2006. 239 p. Orientações curriculares para o ensino médio; volume 1. 2006.

BOISVERT, D. L.i; SLEZ, B. J. The Relationship between Visitor Characteristics and LearningAssociated Behaviors in a Science Museum Discovery Space. Hoboken: Science Education. 137-148, 1994.

COSTA, R. G. A. Os saberes populares da etnociência no ensino das ciências naturais: uma proposta didática para aprendizagem significativa. Revista Didática Sistêmica (Online), v. 8, p. 162-171, 2008.

DIAS, G. F. Educação Ambiental: Princípios e Práticas. São Paulo. Gaia. 2004.

DIEGUES, A.C.S. O mito da natureza intocada. 4 ed. São Paulo, Annablume, 2002.

FREIRE, A. M. A. Inédito Viável. In: STRECK, Danilo; REDIM, Euclides; ZITKOSKI, Jaime Jose (orgs). Dicionário Paulo Freire. 2. ed. Belo Horizonte: Autêntica, 2010. p. 223-226.

GOHN, M. da G. Educação não-formal, participação da sociedade civil e estruturas colegiadas nas escolas. Ensaio: aval. pol. públ. Educ. Rio de Janeiro, v.14, n.50, p 27-38, jan./mar. 2006.

RIBEIRO, Darcy. O povo brasileiro: a formação e o sentido do Brasil. São Paulo: Companhia das Letras,1995.

MARANDINO, M. Transposição ou recontextualização? Sobre a produção de saberes na educação em museus de ciências. Revista Brasileira de Educação. v. 26, 2004.

KRASILCHIK, M. Prática de Ensino de Biologia. São Paulo: Edusp. 2008. 
SABBATINI, M. Museus e centros de ciência virtuais: uma nova fronteira para a cultura científica. Comciência, Campinas, n. 45, p. 1-6, 2003. 